REVIEW

\title{
Is coronary heart disease rising in India? A systematic review based on ECG defined coronary heart disease
}

\author{
N Ahmad, R Bhopal
}

Heart 2005;91:719-725. doi: 10.1136/hrt.2003.031047

The aim of this study was to investigate whether coronary heart disease (CHD) is rising in India and assess the quality of the evidence. Thirty one studies were reviewed. The sample sizes of the studies varied from approximately 500 to 14000 , with response rates generally over $90 \%$. Many did not fulfil basic requirements for epidemiological research and most studies were in or around Delhi. The three incidence studies used different diagnostic criteria; however, the incidence of myocardial infarction (MI) in urban India in the 14 years to 1991 remained similar at about 6/1000 in males and 2/1000 in females.

Prevalence range was higher in urban than rural areas in men (35-90/1000 v 17-45/1000) and women (28-93/ 1000 v 13-43/1000). There was no clear rise in age specific rates in men over a 27 year period, whereas a rise was seen in women. In conclusion, using a relatively objective measure of CHD it was found that CHD is more common in urban than rural areas of India, but there was little evidence of a rise in CHD over time, especially in men.

See end of article for authors' affiliations

Correspondence to:

Dr Naseer Ahmad, 4 Hyldavale Avenue, Gatlay, Cheadle, Stockport SK8 4DE, UK; naseer102@ hotmail.com

Accepted 7 July 2004

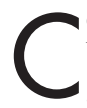
oronary heart disease (CHD) is forecast to be the most common cause of death globally, including India, by $2020 .{ }^{1}$ CHD is high among people with Indian origins who are now living abroad..$^{2-6}$

Gupta and $\mathrm{Gupta}^{7}$ reviewed studies determining CHD prevalence in India. They found that CHD prevalence increased in urban areas from $1 \%$ in the 1960 s to $9 \%$ in the 1990 s. In rural areas the rate increased from $2 \%$ in the 1970 s to $4 \%$ in the 1990s. Their meta-analysis did not comment upon the quality of the studies included and did not separate the prevalence on clinical data, and clinical and ECG data. Their conclusions, therefore, need re-examination.

To investigate how common the disease was we reviewed data published in journals (including the prevalence data used in Gupta's report) on the frequency of CHD in India. To increase comparability we focused on studies including Minnesota coded ECG as part of the definition of CHD.

\section{METHODS}

We searched Medline between 1966 and March 2003 and Embase between 1980 and March 2003 using the following text words and MeSH headings: India\$ or Asia\$ and heart or coronary disease or myocardial infarction or angina. We then examined the citations in the papers found to identify studies not indexed by Medline or Embase. Studies were limited to those published in English language journals and based on populations residing in India. We also searched RSB's personal collection of books and papers on the subject as well as the World Health Organization $^{8}$ and Global Cardiovascular Infobase $^{9}$ websites during March 2003. We extracted data from community based research.

Our search highlighted 3278 references. After removing duplicates and those not obviously relating to $\mathrm{CHD}$ frequency, 336 potentially relevant references remained of which 305 were excluded (list of rejected studies available from the authors) as follows: 24 outside India, 33 were hospital studies, 15 CHD was not defined using ECG, 96 measured CHD risk factors, 11 were on diseased populations (for example, diabetic patients), 23 examined CHD prevention or treatment strategies, 60 summarised data in the form of reviews, and 43 were on other topics (for example, case reports). We focused on studies conducted after 1960 because the Minnesota code was published in $1969 .{ }^{10}$ The first Indian study using the Minnesota code was published in 1974. ${ }^{11}$

The hospital studies were excluded from this review as they did not permit robust conclusions because they were from cities from several regions and from different types of hospital. No study commented upon the accuracy of data and few stated diagnostic criteria. Many did not state type of hospital, location, or catchment area. While CHD comprised 0-2\% of all admissions in the 1950s, it comprised about $10 \%$ in the 1970 s and 1980s.

Community studies generally included both symptomatic and asymptomatic individuals. Asymptomatic CHD cases had characteristic changes on the ECG but no symptoms. Of the nine studies presenting data from the asymptomatic population, only three ${ }^{12-14}$ detailed how this population was defined-that is, whether negative on the Rose questionnaire or without clinical history. Most studies used Minnesota codes 1.1.1-1.1.7, 1.2.1-1.2.7 (pathological Q), 4.1.1, 4.1.2 (ST depression), or 5.1, 5.2 (T wave inversion) to define CHD. However, some studies used the additional ST change code $9.2^{15-18}$ in their definition and occasionally included clinical cases. ${ }^{19}{ }^{20}$ One did not include $t$ wave inversion data in their definition. ${ }^{20}$ Probable CHD was, therefore, not defined absolutely consistently.

We extracted the following information from publications: time and location of fieldwork, criteria for diagnosing $\mathrm{CHD}$, method of determining 
Table 1 Summary of methods and results of incidence and mortality studies examining CHD frequency in India

\begin{tabular}{|c|c|c|c|c|}
\hline & Incidence & \multicolumn{2}{|l|}{ Prevalence } & Mortality \\
\hline Number reviewed $(n=31)$ & $n=3$ & \multicolumn{2}{|l|}{$n=27$} & $n=1$ \\
\hline Timing & 1977-1992 & \multicolumn{2}{|l|}{$1974-2002$} & \multirow{2}{*}{$\begin{array}{l}\text { 1958-1962 } \\
\text { Mortality/100000 }\end{array}$} \\
\hline Main outcome & $\begin{array}{l}\text { New cases of } \mathrm{MI} \text { or } \mathrm{CHD} \text { per } 1000 \\
\text { population }\end{array}$ & \multicolumn{2}{|c|}{$\begin{array}{l}\text { Prevalence of probable CHD on ECG per } 1000 \\
\text { population }\end{array}$} & \\
\hline Source of diagnosis data & $\begin{array}{l}\text { Hospital records and/or individual } \\
\text { follow up }\end{array}$ & \multicolumn{2}{|l|}{ ECG (Minnesota coded) } & Death certificates \\
\hline \multirow[t]{8}{*}{ Range } & $\mathrm{Ml}$ & \multicolumn{2}{|c|}{ Probable* (symptomatic and asymptomatic) } & \multirow[t]{8}{*}{ Males 20-135 } \\
\hline & Males 4-6 & Urban & Rural & \\
\hline & Females 2 & Males & $17-45$ & \\
\hline & & Females & $13-43$ & \\
\hline & & Probable (asymptomatic)† & & \\
\hline & & Urban & Rural & \\
\hline & & Males & $6-18$ & \\
\hline & & Females & $11-34$ & \\
\hline \multirow[t]{15}{*}{$\begin{array}{l}\text { Results for incidence and } \\
\text { mortality (see table } 2 \text { and } 3 \text { for } \\
\text { prevalence) }\end{array}$} & Gupta $^{41}$ ( $\geqslant 30$ years) & & & \multirow{15}{*}{$\begin{array}{l}\text { Malhotra }^{37} \text { (18-55 years) } \\
8 \text { Indian railway regions, } \\
1958-1962 \\
\text { Men } \\
\text { Northern } 20 \\
\text { Southern } 135 \\
\text { All } 59\end{array}$} \\
\hline & Urban Rohtak, 1977-1978; MI & & & \\
\hline & Men 6 & & & \\
\hline & Women 2 & & & \\
\hline & & & & \\
\hline & Chadha $^{42}$ (25-64 years) & & & \\
\hline & Urban Delhi, 1990-1991; MI & & & \\
\hline & Men 4 & & & \\
\hline & Women 2 & & & \\
\hline & Trivedi $^{38}$ (30-62 years) & & & \\
\hline & Rural Gujrat, 1987-1992; CHD & & & \\
\hline & Men and women & & & \\
\hline & $1987-1988$ & & & \\
\hline & $1991-1992$ & & & \\
\hline & Average annual rate 5 & & & \\
\hline
\end{tabular}

*Based on Minnesota coded ECG; studies were assumed to present data from the symptomatic and asymptomatic unless stated otherwise.

†Subjects who respond negatively to the Rose angina questionnaire and/or are known not to have CHD but have ECG changes of probable CHD.

$\mathrm{CHD}$, coronary heart disease; MI, myocardial infarction.

denominator populations, technique of selecting sample, age range of subjects, response rates, and the rate of CHD in males, females, and both combined. The incidence and prevalence rates were rounded to the nearest integer and expressed per 1000, and mortality rates per 100000 .

The quality of the totality of publications was judged on basic requirements of epidemiological design (for example, whether location and date of fieldwork was given), the definition of the measures of disease and hence accuracy of the numerator, the source and accuracy of the denominator, sampling strategy, response rates, and definitions used to do subgroup analysis by ethnic or religious group. ${ }^{21}$

\section{RESULTS}

\section{Community based studies}

For ease of reference, studies will be referred to in the text by their number in the table under consideration, shown in brackets. The methods employed in the included studies are tabulated in the appendix (table Al) (to view the appendix please visit the Heart website-http://www.heartjnl.com/ supplemental).

\section{Location of Studies}

Table 1 shows there were three studies on incidence, 27 on prevalence, and one on mortality. Of these, 28 were from North India, mostly around Delhi, the capital of India (fig l). Mortality data were only on Indian men.

\section{Observations on methods of community studies}

Of 31 studies, 21 did not state the date of fieldwork ${ }^{11} 13$ 15-19 22-35 (table Al, studies 4-6, 8, 11-15,17-24, 26, and 28-30). Three studies used the census to define study areas and denominators $^{19} 27{ }^{36}$ (table Al, studies 14, 16, and 18) though the accuracy outside the census year is questionable. Malhotra $^{37}$ (table Al, study 31 ) determined the denominator for his railway mortality study from pay roll data. Trivedi ${ }^{38}$ (table Al, study 3) provided detailed information on the method of sampling.

The response rate was sometimes near $100 \%$ and generally over $85 \%$, although lower in females (table Al, studies 12, 17, 20, 24, and 29). There was dual publication of data. Two urban datasets supplied six papers ${ }^{13} 2934363940$ (table Al, studies 7, 9, and 16 and studies 17, 21, and 29). One rural dataset supplied four papers ${ }^{15} 172931$ (table Al, studies 12, 20, 21 , and 24).

None of the three studies reporting ethnic differences ${ }^{12} 3436$ (table Al, studies 10, 16, and 29) indicated the criteria for categorising people into different ethnic groups.

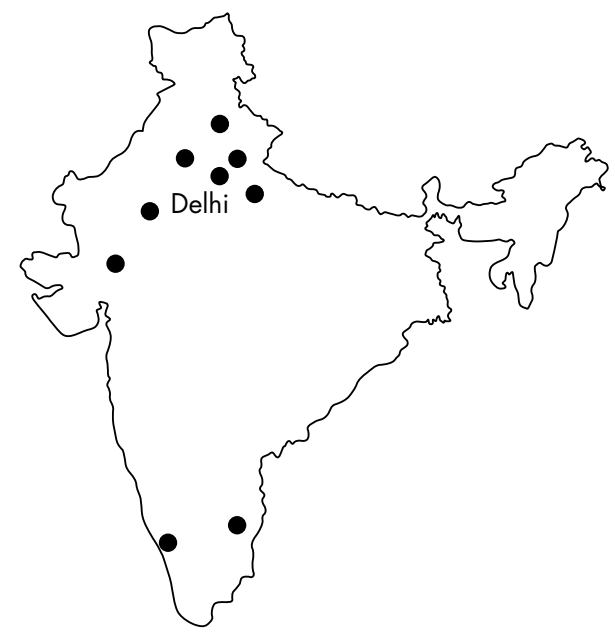

Figure 1 Map of India showing location of areas studied. 


\section{Findings of community studies: incidence}

The three incidence studies used different methods to attain data and so are not directly comparable. However, Gupta and Khetrapaul $^{41}$ (register based study) and Chadha et a ${ }^{42}$ (cohort study) describe a similar incidence of MI 14 years apart. The decreasing incidence in the Trivedi and co-workers cohort study $^{38}$, from 6/1000 to $3 / 1000$, probably reflects early cases arising in people with prevalent disease, possibly exacerbated by including 172 volunteers, who may have had high risk of CHD.

\section{Findings of community studies: prevalence of probable CHD in Indian urban and rural areas}

Over the 27 year period represented in table 2, there was little evidence of a rise in prevalence in urban areas, particularly in men. Evidence suggesting an increased urban prevalence over time in women in the symptomatic and asymptomatic population came from Gupta and Malhotra ${ }^{22}$ (table 2, study 1) and Gupta et $a^{13}$ (table 2, study 2) where rates were 28/ 1000 in 1975 and 84/1000 in 1995 respectively. Gupta et al ${ }^{35}$ (table 2, study 8) measured prevalence in the same population (but not the same individuals) approximately eight years after the initial study ${ }^{13}$ (table 2, study 2). They found no increase in the prevalence of CHD in men or women. Of the five studies presenting data from asymptomatic populations, two reported from the same dataset (table 2, studies 10 and 12) with rates of 56/1000 in men and $76 / 1000$ in women; the remaining three (table 2, studies 9 , 11 , and 13) reported rates between $25 / 1000$ and $77 / 1000$ in men and 31/1000 and 56/1000 in women with no trend. The study of Singh and co-workers in Moradabad (table 2, study 11) was not directly comparable with the other urban studies as their population was all over 49 years old.

In the rural studies (table 3), again the evidence for a rise in prevalence was very limited. Assessing change over time was tentatively possible between Deewan et $\mathrm{al}^{11}$ (table 3, study 1) and Wander et al $^{19}$ (table 3 , study 3 ). Neither gave fieldwork dates but were published 20 years apart. Prevalence of probable CHD in the symptomatic and asymptomatic populations increased from $17 / 1000$ to $26 / 1000$ in men and $13 / 1000$ to $38 / 1000$ in women. Among the asymptomatic population, prevalence appeared to decrease over time, at least in women. Jajoo et $a^{23}$ (table 3, study 8), reported prevalence as 34/1000 in 1988 and this decreased by 1997 to between 11/1000 and 27/1000 as reported by Singh et al ${ }^{18}$ (table 3, study 11) and Chadha et $a l^{14}$ (table 3, study 10), respectively. Only Chadha et al $^{14}$ (table 3, study 10) gave fieldwork dates. Of the 10 studies that gave both male and female rates, six (table 3, studies 2, 3, 7-10) reported rates higher in females than males of between $20 \%$ (table 3 , studies 2 and 4 ) and $450 \%$ (table 3, study 10). Artefacts, particularly the validity of the ECG in the diagnosis of CHD, need to be considered with such a female excess.

Three studies explicitly compared urban and rural prevalence rates. The urban prevalence of Gupta and Malhotra ${ }^{22}$ (table 2, study 1) was higher than Deewan et $\mathrm{al}^{11}$ (table 3, study 1) rural prevalence in men (45/1000 $v 17 / 1000)$ and women $(28 / 1000 v 13 / 1000)$. Chadha ${ }^{14}$ compared the asymptomatic urban (table 2, study 10) and rural Delhi population (table 3, study 10) and found rates to be higher in urban

Table 2 Urban prevalence rates of probable CHD per 1000, in males and females

\begin{tabular}{|c|c|c|c|c|c|}
\hline Study number & $\begin{array}{l}\text { Author/date } \\
\text { publication }\end{array}$ & $\begin{array}{l}\text { Location and } \\
\text { date of fieldwork }\end{array}$ & Group & Male & Female \\
\hline \multicolumn{6}{|c|}{$\begin{array}{l}\text { Symptomatic and } \\
\text { asymptomatic }\end{array}$} \\
\hline 1 & Gupta $1975^{22}$ & $\begin{array}{l}\text { Rohtak, Haryana, } \\
\text { dates not given }\end{array}$ & Adults $>30$ years & 45 & 28 \\
\hline $2^{*} \dagger$ & Gupta $1995^{13}$ & $\begin{array}{l}\text { Rajasthan, } \\
\text { dates not given }\end{array}$ & Adults $>20$ years & 35 & 84 \\
\hline $3^{*}$ & Gupta $1996^{29}$ & $\begin{array}{l}\text { Rajasthan, } \\
\text { dates not given }\end{array}$ & Adult males $>20$ years & 35 & NS \\
\hline 4 & Singh $1998^{32}$ & $\begin{array}{l}\text { Moradabad, } \\
\text { dates not given }\end{array}$ & Adults $25-64$ years & 90 & 60 \\
\hline $5 \ddagger$ & $\begin{array}{l}\text { Ramachadran } \\
1998^{20}\end{array}$ & Madras, 1994 & Adults $>40$ years & 35 & 45 \\
\hline 6 & Mohan $2001^{33}$ & $\begin{array}{l}\text { Chennai (formerly } \\
\text { Madras), dates } \\
\text { not given }\end{array}$ & Adults $>20$ years & 62 & 93 \\
\hline $7^{*}$ & Gupta $2002^{34}$ & $\begin{array}{l}\text { Rajasthan, } \\
\text { dates not given }\end{array}$ & $\begin{array}{l}\text { Adults }>20 \text { years } \\
\text { Hindu }\end{array}$ & 43 & 89 \\
\hline $8 \dagger$ & Gupta $2002^{35}$ & $\begin{array}{l}\text { Rajasthan, } \\
\text { dates not given }\end{array}$ & Adults $>20$ years & 38 & $\begin{array}{l}00 \\
72\end{array}$ \\
\hline \multicolumn{6}{|l|}{ Asymptomatic } \\
\hline 9 & Chadha $1992^{12}$ & Delhi, 1988 & $\begin{array}{l}\text { Adults } 25-64 \text { years } \\
\text { Gujeratis }\end{array}$ & 67 & 31 \\
\hline $10 \S$ & Gopianth $1992^{40}$ & Delhi, 1985-1987 & Adults $25-64$ years & 56 & 76 \\
\hline 11 & Singh $1995^{27}$ & $\begin{array}{l}\text { Moradabad, } \\
\text { dates not given }\end{array}$ & Adults $>49$ years & 77 & 56 \\
\hline \multirow[t]{6}{*}{$12 \ddagger$} & Gopianth $1996^{36}$ & Delhi, 1985-1987 & $\begin{array}{l}\text { Adults } 25-64 \text { years } \\
\text { Asymptomatic }\end{array}$ & & \\
\hline & & & Hindus & 50 & 61 \\
\hline & & & Muslims & 95 & 85 \\
\hline & & & Sikhs & 54 & 114 \\
\hline & & & Christians & & 48 \\
\hline & & & All & 56 & 76 \\
\hline 13 & Singh $1997^{18}$ & $\begin{array}{l}\text { Rural and urban } \\
\text { Moradabad, } \\
\text { dates not given }\end{array}$ & Adults $25-64$ years & 25 & 34 \\
\hline \multicolumn{6}{|c|}{$\begin{array}{l}\text { * Use the same dataset; } † \text { studies } 2 \text { and } 8 \text { are the prevalence rates of the same population, but not the same } \\
\text { individuals, measured years later; } ¥ \mathrm{~T} \text { wave inversion data not given in sex prevalence (accounts for an extra } 10 \% \\
\mathrm{CHD} \text { in combined male/female rate); Suses the same dataset (Chadha } 1990^{39} \text { also uses the same dataset but thi } \\
\text { data is not in the table as individual male and female rates were not given); NS, not stated. }\end{array}$} \\
\hline
\end{tabular}


Table 3 Rural prevalence rates of probable CHD per 1000 in males and females

\begin{tabular}{|c|c|c|c|c|c|}
\hline Study number & Author/date publication & Location and date of fieldwork & Group & Male & Female \\
\hline \multicolumn{6}{|c|}{$\begin{array}{l}\text { Symptomatic and } \\
\text { asymptomatic }\end{array}$} \\
\hline 1 & Dewan $1974^{11}$ & Haryana, dates not given & Adults $>30$ years & 17 & 13 \\
\hline $2^{*}$ & Gupta $1994^{15}$ & Rajasthan, dates not given & Adults $>20$ years & 28 & 33 \\
\hline 3 & Wander $1994^{19}$ & Punjab, dates not given & Adults $>30$ years & 26 & 38 \\
\hline 4 & Gupta $1994^{16}$ & Rajasthan, dates not given & Adults $>25$ years & 45 & 43 \\
\hline $5^{*}$ & Gupta $1996^{29}$ & Rajasthan, dates not given & Adults $>20$ years & 28 & NS \\
\hline 6 & Singh $1997^{30}$ & Moradabad, dates not given & Adults $25-64$ years & 33 & 20 \\
\hline $7^{*}$ & Gupta $1997^{31}$ & Rajasthan, dates not given & Adults $>20$ years & 28 & 33 \\
\hline \multicolumn{6}{|l|}{ Asymptomatic } \\
\hline 8 & Jajoo $1988^{23}$ & Sevagram, dates not given & Adults $>30$ years & 17 & 34 \\
\hline 9* & Gupta $1996^{17}$ & Rajasthan, dates not given & Adults $>20$ years & 13 & 24 \\
\hline 10 & Chadha $1997^{14}$ & Delhi, 1984-1987 & Adults $25-64$ years & 6 & 27 \\
\hline 11 & Singh $1997^{18}$ & $\begin{array}{l}\text { Rural and urban Moradabad, } \\
\text { dates not given }\end{array}$ & Adults $25-64$ years & 18 & 11 \\
\hline
\end{tabular}

Delhi men (56/1000 $v 6 / 1000)$ and women (76/1000 $v 27 /$ 1000) compared with their rural counterparts. Singh et a ${ }^{18}$ also found a similar pattern in the urban (table 2, study 13) and rural (table 3, study 11) asymptomatic Moradabad population (men 25/1000 v 18/1000; women 34/1000 $v 11 /$ 1000). Urban prevalence rates therefore exceeded rural rates by between $40 \%$ and $900 \%$ in men and between $220 \%$ and $300 \%$ in women.

No studies presenting ECG defined CHD explicitly compared rates between North and South India. South Indian prevalence rates were not consistently higher than North India (table 2, studies 5 and 6). ${ }^{20}{ }^{33}$ However, Beegom and Singh $^{28}$ (table Al, study 19 ) found the rates of MI (clinical CHD; defined using the Rose angina questionnaire) to be higher in both South Indian males (174/1000 v 100/1000) and females $(102 / 1000 v 69 / 1000)$ than North Indians.

\section{Ethnic groups in India}

Few studies reported on Indian ethnic subgroups, with some suggestion of heterogeneity. Gopianth ${ }^{36}$ (table 2, study 12) reported on the asymptomatic Delhi population by religious group without stating how religion was determined. Among the male population, Muslims experienced the highest rates (95/1000) with no cases in Christian men. Hindus and Sikhs had similar rates (50/1000 and 54/1000, respectively). Among females, Sikhs experienced the highest rate (114/1000), Christians the lowest (48/1000; but only comprised $0.9 \%$ of the study population) while Muslims and Hindus had rates in between (85/1000 and 61/1000 respectively). Gupta et al $^{34}$ (table 2, study 7) found rates to be higher in Hindus, particularly men, than Muslims but there were only two cases in the 272 Muslim men. Chadha et al ${ }^{12}$ and Gopianth et a $^{40}$ (table 2, studies 9 and 10) found that Gujerati males in Delhi had a prevalence rate that was higher than the general population (67/1000 v 56/1000) whereas Gujerati females had a lower rate compared with their counterparts (31/1000 $v 76$ / $1000)$.

\section{Comparison over time in age specific prevalence rates} Five urban (table 4) and five rural (table 5) studies reported prevalence of probable CHD by age groups. Only one gave a date for fieldwork. Among the symptomatic and asymptomatic urban populations, Gupta et $a l^{13}$ (table 4, study 2) and Gupta et $a l^{35}$ (table 4, study 3) published prevalence in the same Rajasthan area some years apart. Although no difference in total prevalence was reported, age specific rates show a decline in males less than 40 years old, but an increase in those aged 40-59 years but no important changes in females. However, comparing Gupta et $\mathrm{al}^{35}$ (table 4, study 3) with Gupta and Malhotra' ${ }^{22}$ (table 4, study 1), over a 27 year period, there appeared to be no difference in age specific rates between males whereas an increase was clear cut in females. Among the asymptomatic urban population (table 4, studies 4 and 5), there was no evidence of a rise in either males or females.

Among the rural population (table 5), a clear cut rise among the symptomatic and asymptomatic females was seen with some evidence of a rise in men.

\section{Mortality from CHD}

The study by Malhotra ${ }^{37}$ is the only study reporting CHD mortality from the Indian subcontinent (table 1). Indian rates were presented by railway zones and ranged from 20/ 100000 to $135 / 100000$ in Northern and Southern railway zones respectively.

\section{DISCUSSION}

\section{Search strategy and methods}

We reviewed 31 studies found by searching Medline and Embase and examining citations. We searched some grey literature-for example, from the World Health Organization website. The World Health Organization statistical information system (WHOSIS) ${ }^{8}$ and Global Cardiovascular Infobase ${ }^{9}$ provide epidemiological profiles of cardiovascular disease internationally. Neither source yielded relevant information, in the case of WHOSIS because death registration was considered to be too low. It is unlikely that additional grey literature sources would yield higher quality information than we found. Much Indian scientific, medical, and academic research uses English, particularly for publication. While our search strategy may have missed work, it seems unlikely that it would give higher quality information than we found, or that our conclusions would have changed substantially. Our search was, therefore, limited to articles in English for pragmatic reasons.

Using ECG based definitions made it possible to compare studies. We have, therefore, focused on ECG defined probable CHD in populations that were asymptomatic or included both asymptomatic and symptomatic people. We excluded studies using only the Rose angina questionnaires because they seldom commented on translation and validation. Without this information we cannot judge the accuracy of the translation or the ability of the population to understand it correctly. ${ }^{43}$ The questionnaire has lesser validity in women ${ }^{44}$ and is probably less valid in non-white populations. ${ }^{45}$ One Indian study concluded that the questionnaire was highly sensitive but not highly specific for angina. ${ }^{24}$

However, ECG based definitions also have limitations. Non-specific ECG changes make interpretation difficult-for example, Q waves, a sign of MI, can be produced by bundle 

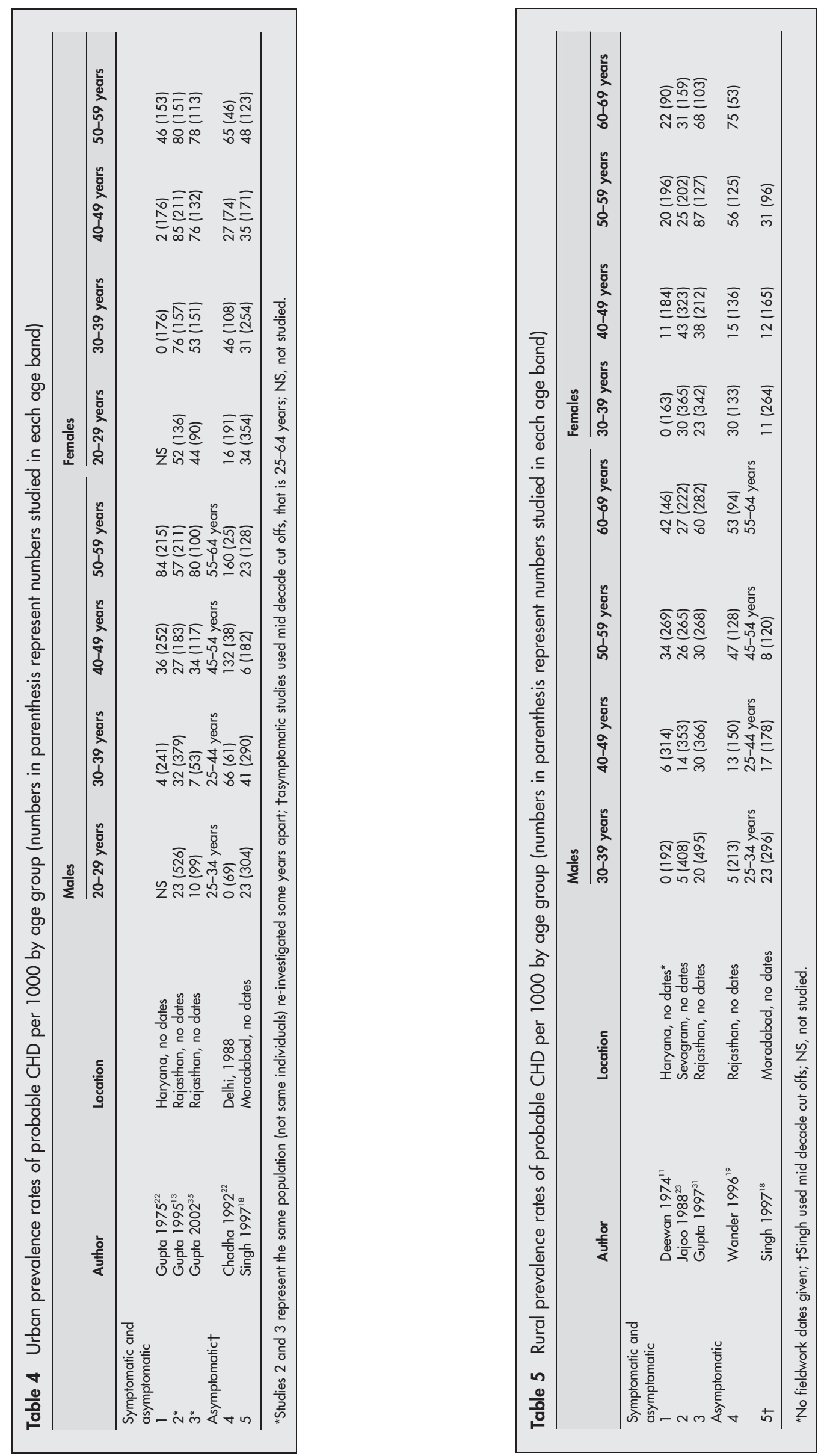

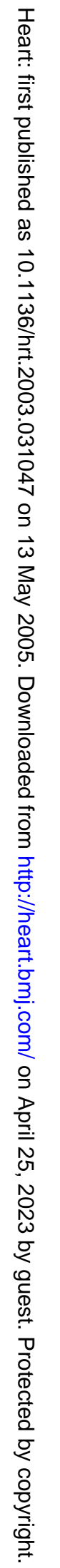


branch block, and flat/inverted T waves in leads II, III and AVF are not necessarily myocardial ischaemia. ${ }^{46}$ ST depression may not have the same diagnostic power in females and may over diagnose. ${ }^{47}$ Patel et al concluded that ECG changes suggestive of ischaemia are common in South Asians and may not be associated with clinical evidence of $\mathrm{CHD}^{48}$ Our finding of more probable CHD in women than men suggests that this may be partially true for women.

Prevalence of CHD measured clinically produces rates higher than that measured solely by Minnesota coded ECG. For example, the prevalence of probable CHD based on ECG, in Moradabad ${ }^{27}$ was 67/1000 but it was $121 / 1000$ when based on clinical and ECG data. A recent review by Gupta ${ }^{7}$ did not take such factors into account. For example, the prevalence in Rohtak in 1975 was reported to be $3.6 \%$ (our calculation was 3.8\%) and 8.6\% in Moradabad in 1995 (table Al, study 21). The Rohtak study presented ECG defined probable CHD whereas clinical CHD was presented in the Moradabad study. To infer an increase over time, as Gupta did, was misleading. This report was cited by the key publication of Yusuf et $a l^{1}$ as demonstrating the alarming increase of CHD in India.

To accurately determine prevalence, a precise baseline denominator and a representative sample of individuals are required. To gauge CHD in India we need studies from across the country. In fact, most have been done in and around Delhi. Five rural studies ${ }^{11} 17192326$ all studied subjects in their chosen area but the study areas were usually chosen because of their proximity to educational institutions. Only three studies ${ }^{13} 3536$ used random number methods to select subjects. The other methods used included blind selection of streets $^{182732}$ (but not houses/individuals), and selecting houses at varying intervals. ${ }^{11} 121422363940$ These methods may not draw random samples.

Generally the studies were large, the number of participants ranging from approximately 500 to 14000 . A power calculation was done in three studies. ${ }^{18} 2739$ These studies assumed prevalence rates of $40 / 1000,{ }^{39} 50 / 1000,{ }^{18}$ and $80 /$ $1000^{27}$ and had sample sizes of 14000,2000 , and 600 . These assumed rates were based on clinical CHD. The two studies accounting for clustering ${ }^{27}{ }^{39}$ did so by doubling the sample size required. The statistical basis upon which this decision was made was not stated. Response rates were high (over $90 \%$ ) and frequently approached $100 \%$. The methods are worthy of deeper examination to understand how such high rates were achieved.

In the studies that examined subgroup differences, no mention was made as to how religious affiliation was assessed $^{34}{ }^{36}$ or how Gujerati identity was established. ${ }^{12}$

\section{Comparisons by time, regional and ethnic/religious subgroups}

The three incidence studies did not show a rise over time Trivedi $^{38}$ reported that the incidence of CHD from the same Gujarat village cohort halved over the years 1987-1992 (6/ 1000 to 3/1000), probably because early cases were arising from the pool of prevalent disease. Trends in prevalence data over a 27 year period were difficult to interpret, partly because many studies did not give dates of fieldwork. This is a major weakness in the set of studies ${ }^{21}$; however, using publication date as a proxy measure the re-examination of prevalence in urban Rajasthan by Gupta et al showed no increase between 1995 and 2002 in either men or women. Overall and age specific prevalence data over a 27 year period suggests an increase in women, and less evidence for changes in men. On the ECG alone, however, the male to female ratio was inconsistent, with female rates exceeding those of men in several studies, especially more recent ones. This most likely reflects the sex differences in the validity of the ECG in diagnosing $\mathrm{CHD}$, though the sex ratio may be changing as the epidemic of CHD affects women more than men.

There are few data on regional variations within India. Malhotra $^{37}$ showed that mortality from CHD differed between employees of Indian railways across railway zones. The rates were lowest in Northern areas (20/100 000), higher in Eastern and central areas (50/100 000 and 63/100 000, respectively) and highest in Southern areas (135/100 000). The lack of mortality studies reflect no uniform completion of death certificates and no centralised death registry for cardiovascular disease ${ }^{49}$ Prevalence data did not accord with such huge variation. Within urban Delhi ${ }^{12}{ }^{36}$ and Rajasthan ${ }^{35}$ there was evidence that prevalence might differ by religion and ethnic group, but larger and more clearly documented studies are needed. The prevalence rates are higher in urban than rural India.

In conclusion, there is a shortage of good quality comparable epidemiological data from India. The evidence does not suggest a rising incidence of CHD to the extent predicted. However, there is evidence of increasing prevalence, mainly in women, but it is based on few studies. India may be on the cusp of an explosive epidemic of CHD, but the evidence for this is weak. The impression of a higher prevalence in recent decades may reflect better clinical diagnosis, more health care facilities, more cases of CHD in hospitals, greater survival, and population aging. There is an urgent need for new epidemiological research in India. Future studies should randomly select subjects, provide dates of fieldwork, be powered to test for variation in time and place, provide age specific and age adjusted rates, diagnose CHD using agreed and consistent definitions, including ECG based measures, and represent more regions of the country.

\section{ACKNOWLEDGEMENTS}

We would like to thank Professor Simon Capewell for comments on a student project of $\mathrm{N}$ Ahmad arising from this research.

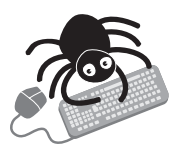

To view the appendix (table A1) please visit the Heart website-http://www.heartinl.com/supplemental

\section{Authors' affiliations}

N Ahmad, Mid Cheshire Hospitals Trust, Crewe, UK

R Bhopal, Division of Community Health Sciences, University of Edinburgh, Edinburgh, UK

\section{REFERENCES}

1 Yusuf S, Reddy S, Ounpuu S, et al. Global burden of cardiovascular disease. Part II. Variations in cardiovascular disease by specific ethnic groups and geographic regions and prevention strategies. Circulation 2001; 104:2855-64.

2 McKeigue PM, Sevak L. Coronary heart disease in South Asian communities. London: Health Education Authority, 1994

3 Smaje C. Health and ethnicity: a review of the literature. London: Kings Fund Institute, 1994

4 Shaukat N, de Bono DP. Are Indo-origin people especially susceptible to coronary artery disease? Postgrad Med J 1994;70:315-8.

5 Enas EA, Yusuf S, Mehta JL. Prevalence of coronary artery disease in Asian Indians. Am J Cardiol 1992;70:945-9.

6 Bhopal R. What is the risk of coronary heart disease in South Asians? A review of UK research. J Public Health Med 2000;22:375-85.

7 Gupta R, Gupta VP. Meta-analysis of coronary heart disease prevalence in India. Indian Heart J 1996;48:241-5.

8 World Health Organisation Statistical Information System (WHOSIS). http:// www3.who.int/whosis/menu.cfm?path = whosis\&language = english, 2003.

9 Global Cardiovascular Infobase. http://cvdinfobase.ic.gc.ca/, 2003.

10 Blackburn H. Electrocardiographic classification for population comparisons. The Minnesota code. J Electrocardiol 1969:52:5-9.

11 Deewan BD, Malhotra KC, Gupta SP. Epidemiological study of coronary heart disease in rural community Haryana. Indian Heart J 1974;26:68-78.

12 Chadha SL, Gopianth N, Ramachadran K. Epidemiological study of coronary heart disease in Gujaratis in Delhi (India). Indian J Med Res 1992;96:1 15-21. 
13 Gupta R, Prakesh H, Majumder S, et al. Prevalence of coronary heart disease and coronary risk factors in an urban population of Rajasthan. Indian Heart $J$ 1995;47:331-8.

14 Chadha SL, Gopianth N, Shekhawat S. Urban-rural differences in the prevalence of coronary heart disease and its risk factors in Delhi. Bull World Health Org 1997;75:31-8.

15 Gupta R, Gupta VP, Ahluwalia NS. Educational status, coronary heart disease, and coronary risk factor prevalence in a rural population of India. BMJ 1994;309:1332-6.

16 Gupta R, Gupta HP, Keswani P, et al. Coronary heart disease and coronary risk fator prevalence in rural Rajasthan. J Assoc Physicians India 1994;42:24-6

17 Gupta R, Sharma S. Prevalence of asymptomatic electrocardiographic abnormalities in a rural population. J Assoc Physicians India 1996;44:775-7.

18 Singh RB, Sharma JP, Rastogi V, et al. Prevalence of coronary artery disease and coronary risk factors in rural and urban populations of north India. Eur Heart J 1997; 18:1728-35.

19 Wander GS, Khurana SB, Gulati R, et al. Epidemiology of coronary heart disease in a rural Punjab population--prevalence and correlation with various risk factors. Indian Heart J 1994;46:319-23.

20 Ramachandran A, Snehalatha C, Latha E, et al. Clustering of cardiovascular risk factors in urban Asian Indians. Diabetes Care 1998;21:967-71.

21 Bhopal R. Some questions relevant to the appraisal of epidemiological research. Concepts of Epidemiology. Oxford: Oxford University Press, 2003:290.

22 Gupta SP, Malhotra KC. Urban-rural trends in the epidemiology of coronary heart disease. J Assoc Physicians India 1975;23:885-92.

23 Jajoo UN, Kalantri SP, Gupta OP, et al. The prevalence of coronary heart disease in rural population from central India. J Assoc Physicians India 1988; 36:689-93.

24 Kutty VR, Balakrishnan KG, Jayasree AK, et al. Prevalence of coronary heart disease in the rural population of Thiruvananthapuram district, Kerala, India. Int J Cardiol 1993;39:59-70.

25 Sharma S. Clinical, biochemical, electrocardiographic and noninvasive hemodynamic assessment of cardiovascular status in natives at high to extreme altitudes $(3000 \mathrm{~m}-5500 \mathrm{~m})$ of the Himalayan region. Indian Heart $J$ 1990;42:375-9.

26 Kaushal SS, DasGupta DJ, Prashar BS, et al. Electrographic manifestations of healthy residents of a tribal Himalayan village. J Assoc Physicians India 1995; 43:15-6.

27 Singh RB, Niaz MA, Ghosh S, et al. Epidemiological study of coronary artery disease and its risk factors in an elderly urban population of north India. J Am Coll Nutr 1995; 14:628-34.

28 Beegom R, Singh RB. Prevalence of coronary artery disease and its risk factors in the urban population of South and North India. Acta Cardiol 1995:50:227-40.

29 Gupta R. Lifestyle risk factors and coronary heart disease prevalence in Indian men. J Assoc Physicians India 1996;44:689-93.

30 Singh RB, Sharma JP, Rastogi V, et al. Social class and coronary disease in rural population of north India. The Indian social class and heart survey. Eur Heart J 1997; 18:588-95.
31 Gupta R, Prakesh H, Gupta VP, et al. Prevalence and determinants or coronary heart disease in a rural population of India. J Clin Epidemiol 1997;50:203-9.

32 Singh RB, Niaz MA, Ghosh S, et al. Low fat intake and coronary artery disease in a population with higher prevalence of coronary artery disease: the Indian paradox. J Am Coll Nutr 1998;17:342-50.

33 Mohan V, Deepa R, Rani SS, for the Chennai Urban Population Study, et al. Prevalence of coronary artery disease and its relationship to lipids in a selected population in South India: The Chennai urban population study (CUPS No. 5). J Am Coll Cardiol 2001;38:682-7.

34 Gupta R, Gupta VP, Prakash H, et al. Hindu-Muslim differences in the prevalence of coronary heart disease and risk factors. I Indian Med Assoc 2002;100:227-30.

35 Gupta R, Gupta VP, Sarna M, et al. Prevalence of coronary heart disease and risk factors in an urban Indian population: Jaipur Heart Watch-2. Indian Heart J 2002;54:59-66.

36 Gopianth N, Chandha SL, Jain P, et al. An epidemiological study of coronary heart disease in different ethnic groups in Delhi urban population. J Assoc Physicians India 1995:43:30-3.

37 Malhotra SL. Epidemiology of ischaemic heart disease in India with special reference to causation. Br Heart J 1967;29:895-905.

38 Trivedi DH, Sharma V, Pandya H, et al. Longitudinal epidemiological study of coronary heart disease in a rural population of Kheda district, Gujarat, India. Soz Praventivmed 1996:41:373-9.

39 Chadha SL, Radhakrishnan S, Ramachadran K, et al. Epidemiological study of coronary heart disease in urban population of Delhi. Indian J Med Res 1990;92:424-30.

40 Gopianth N, Kaul U, Chandha SL, et al. Asymptomatic coronary heart disease detected on epidemiological survey of urban population of Delhi. Indian Heart J 1992;44:95-8.

41 Gupta SP, Khetrapaul NK. Incidence of acute myocardial infarction and sudden death in Rohtak City. J Assoc Physicians India 1981;29:365-72.

42 Chadha SL, Ramachadran K, Shekhawat S, et al. A 3 year follow up study of coronary heart disease in Delhi. Bull World Health Org 1993;71:67-72.

43 Rose GA. The diagnosis of 'ischaemic' heart pain and intermittent claudication in field surveys. Bull World Health Org 1962;27:645-58.

44 Harris RB, Weissfield LA. Gender differences in the reliability of reporting symptoms of angina pectoris. J Clin Epidemiol 1991:44:1071-8.

45 Fischbacher CM, Bhopal R, Unwin N, et al. The performance of the Rose angina questionnaire in South Asian and European origin populations: a comparative study in Newcastle, UK. Int J Epidemiol 2001;30:1009-16.

46 Higgins ITT, Kanel WB, Daeber TR. The ECG in epidemiological studies, reproducibility, validity and international comparison. Br J Prev Soc Med 1965; 19:53-68.

47 Rossouw JE, Weich HFH, Steyn K, et al. The prevalence of ischaemic heart disease in three rural South African communities. J Chronic Dis 1984; $37: 37-106$

48 Patel DJ, Winterbotham M, Sutherland SE, et al. Comparison of methods to assess coronary heart disease prevalence in South Asians. Natl Med J India 1997; 10:210-3.

49 Reddy KS. Cardiovascular diseases in India. World Health Stat Q 1993:46:101-7.

\section{ELECTRONIC PAGES}

\section{Heart Online case reports: www.heartjnl.com}

$\mathrm{T}$

he following electronic only articles are published in conjunction with this issue of Heart.

\section{Complications of supra-annular mitral valve placement in infants}

C L Barker, P E F Daubeney, E A Shinebourne

Two infants underwent supra-annular placement of prosthetic mitral valves. The objective of this strategy was to insert a larger valve and delay replacement. This approach was initially successful but by two and three years later the patients developed impairment of cardiac function. The prosthesis decreased the volume and compliance of the left atrium causing high left atrial and pulmonary venous pressures. The "ventricularised" atrium below the prosthesis dilated. In neither case was it possible to delay second valve replacement.
(Heart 2005;91:e48) www.heartjnl.com/cgi/content/full/91/ 6/e48

\section{Left atrial myxoma in transplanted heart}

W W Yap, K Bhattacharya, V Pathi

Primary cardiac tumours are discovered in about 1 in 2000 necropsies. Cardiac myxomas make up half of all benign intracardiac tumours. Seventy five per cent are located in the left atrium. The first left atrial myxoma arising from the left atrium of a transplanted heart is reported.

(Heart 2005;91:e49) www.heartjnl.com/cgi/content/full/91/ 6/e49 